\title{
Identifying the Needs of Gen Y by Exploring Their Value Systems: A Qualitative Study
}

\author{
Ipek Altinbasak-Farina and Gozde Guleryuz-Turkel
}

\begin{abstract}
This paper aims to examine the value system of Gen Y (individuals born between 1977-1994) who are in professional life in Turkey, to provide strategic insights to researchers and marketing managers. Qualitative research techniques are used to get deeper insight about the phenomenon. In depth and focus group interviews are realized with a total of 40 respondents following a structured discussion outline. The results are analyzed through content analysis and are expected to form the basis for a future quantitative study. Although the results have similarities with the findings of previous research, specific values particular to Turkey such as "respect," "need for trust in others," "being well groomed," "hardworking," "responsibility" have been identified. Generation $Y$ is a very significant and powerful consumer group in the world in terms of purchasing power and setting the trends. Thus their needs and wants should be understood to anticipate their behaviors and attitudes toward a product, a campaign, brand or company.
\end{abstract}

Index Terms-Generation Y, millennials, values, qualitative research, content analysis, marketing management.

\section{INTRODUCTION}

The marketing managers try to figure out the prominent values of their target group in order to offer them the most appealing products and services. Values are crucial to explain social and personal organization and change. The need to understand the value systems of different cultures have long existed in different disciplines like sociology, psychology, anthropology, and related disciplines such as marketing. Values are used to characterize cultural groups,societies, and individuals, to trace change over time, and to explain the motivational bases of attitudes and behavior [1]. On the other hand, generational cohort marketing is gaining importance in defining marketing strategy since demographics alone are not enough to describe the target markets and generational cohorts reinterpret life stages because cohort members share similar values [2]. Due to the fact that each cohort group has unique values, marketers need to focus on these values in designing products, planning marketing executions and developing promotional strategies [3]. Among the most salient issues

Manuscript received August 14, 2015; revised November 25, 2015.

IpekAltinbasak-Farina is with the Faculty of Economics, Administrative and Social Sciences at Bahcesehir University, Istanbul, Turkey (e-mail: ipek.altinbasak@eas.bahcesehir.edu.tr).

GozdeGuleryuz-Turkel is with the Bahcesehir University, Istanbul, Turkey (e-mail: guleryuzgzd@gmail.com). that generational values may help are market analysis and segmentation, product planning, promotional strategy and public policy and society [4]. Investigating the values of a generational cohort is believed to provide valuable information in grouping the consumers to predict their attitudes and behaviors; to understand their decision making process and their reason to buy. Generation $\mathrm{Y}$ is forming the most crowded generational cohort. According to a recent report of by Insites Consulting; their influence over politics, society and business will even grow in the future (2014). Generation $\mathrm{Y}$ is approximately 25 million in Turkey and will have an important say on the future of Turkey in local and global arena as well [5]. According to the classification of Gen Yers age, one part of the Y Gen is still in the education process whereas the other part have graduated and entered to the professional life. It is believed that there can be differences in terms of values for the studying and working group of Gen Y. In this study it is aimed to find out the values of Gen Yers who are already in the work environment.

\section{VALUES}

Values are the core of personal identity and play a key role in shaping consumer attitudes and behaviors [6]. According to Schwartz (1994), "values are desirable transsituational goals that serve as guiding principles in the life of a person or social entity [7]. Meglino and Ravlin (1998) state that "values specify an individual's personal beliefs about how he or she 'should' or 'ought' to behave in his or her social environments" [8]. Rintamaki et al. (2006) define values as "outcomes of evaluative judgments" and underline that they are used for defining standards, norms, goals and ideals [9].

Analyzing the value and belief system of the human beings is not only a need in social and business life but also crucial for decision makers in finance, marketing, politics, psychology, sociology and anthropology fields while making inferences about consumer behaviors, economic developments, religious choices, society, cultures and cultural changes.

Grouping people and trying to figure out the similarities in their attitudes, beliefs and values are important for marketers so as to develop the best marketing strategy. Understanding the attitudes is critical since attitudes are beliefs about specific objects and situations, and tendencies to evaluate particular objects positively or negatively. On the other side, values are abstract, general and evaluative, transcend specific situations, and are more long lasting [10]. Beliefs, attitudes, and values; all three are results and attributes that shape purchasing behavior, goals and ideals 
for shopping [9].

In the literature it is observed that the researchers have attempted to examine the prominent values of individuals through different scales and measurements. (ie. Rokeach, Kahle, Schwartz). Rokeach defined value as an "enduring prescriptive or proscriptive belief that a specific end state of existence or specific mode of conduct is preferred to an opposite and state or mode of conduct" [10], [11]. He designed a scale to measure these two different sets of values. One set is composed of 18 terminal values which are desired end states of existence and the other set is composed of 18 instrumental which are preferable modes of behavior [12].

Kahle (1983) developed the List of Values (LOV) which has three dimensions and nine items in total; internal values (self-fulfillment, self-respect, sense of accomplishment, and warm relationships with others), external values (security, sense of belonging, and being-well respected), and interpersonal values (fun and enjoyment in life and excitement) [12].

Schwartz in 1988 designed a value survey composed of ten motivational value types and 56 items. He dropped one item in the 56-item and added two others in 1994 [13]. His survey is composed of 3 universal requirements at the root of values: needs of individuals as biological organisms, requisites of coordinating social interaction, and requirements for the functioning of society and the survival of groups [14]. These ten motivational value items are summarized in the Table I.

Values influence the human cognition, attitude and behavior. However, it must be admitted that the values which are subjective in nature will change from culture to culture and even the interpretation of the same value may be different in different cultures. Therefore, it is worth investigating the values in different cultures and make comparisons in order to understand the customers situated in different geographical areas. That's why examining values may provide valuable information for several disciplines including marketing.

\section{Generation Y-MiLLENNIALS}

Generation is a type of national subculture that reflects the value priorities [15]. The members of a generational subculture has similar beliefs, values, attitudes, and logical processes, which shape their way of thinking, acting, reasoning, processing information, working, organizing, and leading [16].

Generation theorists presume that changes in the macroenvironment influence the profile of people born in a specific time period, imprinting a specific and common purchasing and consumption behavior [17]. As a result it is adequate to say that generation theory is critical for marketers and managers. It is important to examine the values of a group of like-minded individuals in order to understand the possible consumption and decision making patterns of consumers. It is vital for managers to the underlying value structure of each generation and differences in values among those generations.

There are four distinguished generations in literature. The Silent Generation (or Veterans; born 1933 to 1945); Baby
Boomers (born 1946 to 1964); Generation X (born 1965 to 1980); and Generation Y/Millennials (born 1981 to 2000). Each generation has unique characteristics, influences, work ethics, core values, and respect and tolerance for others [18].

TABLE I: 10 Motivational VALUE TYPES OF SCHWARTZ'S VALUE SURVEY AND THEIR DEFINING GoALS [13].

\begin{tabular}{|l|c|l|}
\hline$\#$ & $\begin{array}{c}\text { MOTIVATIONAI } \\
\text { VALUE TYPES }\end{array}$ & \multicolumn{1}{|c|}{ DEFINING GOAL } \\
\hline 1 & $\begin{array}{c}\text { SELF } \\
\text { DIRECTION }\end{array}$ & $\begin{array}{l}\text { Independent thought and action - } \\
\text { choosing, creating, exploring. }\end{array}$ \\
\hline 2 & STIMULATION & Excitement, novelty, and challenge in life. \\
\hline 3 & HEDONISM & $\begin{array}{l}\text { Pleasure or sensuous gratification for } \\
\text { oneself. }\end{array}$ \\
\hline 4 & ACHIEVEMENT & $\begin{array}{l}\text { Personal success through demonstrating } \\
\text { competence according to social standards. }\end{array}$ \\
\hline 5 & POWER & $\begin{array}{l}\text { Social status and prestige, control or } \\
\text { dominance over people and resources. }\end{array}$ \\
\hline 6 & SECURITY & $\begin{array}{l}\text { Safety, harmony, and stability of society, } \\
\text { of relationships, and of self. }\end{array}$ \\
\hline 7 & CONFORMITY & $\begin{array}{l}\text { Restraint of actions, inclinations, and } \\
\text { impulses likely to upset or harm others and } \\
\text { violate social expectations or norms. }\end{array}$ \\
\hline 9 & TRADITION & $\begin{array}{l}\text { Respect, commitment, and acceptance of } \\
\text { the customs and ideas that one's culture or } \\
\text { religion provides }\end{array}$ \\
\hline 10 & BENEVOLENCE & $\begin{array}{l}\text { Preserving and enhancing the welfare of } \\
\text { those with whom one is in frequent } \\
\text { personal contact (the 'in-group'). }\end{array}$ \\
\hline
\end{tabular}

Actually, there is no consensus regarding the time interval that defines Generation Yers period among researchers; According to (2011), 1980-2000; Cekada (2012), 19812000; Tulgan and Martin (2006), 1978-1989; Kavounis (2008), 1982-1994; Howe and Strauss (2000), 1982-2000 or Schiffman and Kanuk(2010), 1977-1994 [17]-[22]. Schiffman and Kanuk (2010) divided Gen Y population into three sub segments based on their ages again; Gen $Y$ adults, Gen $Y$ teens and Gen $Y$ kids. In this study the working adult Gen Yers' perceptions are investigated [22]. The participants' age interval is between 24 and 34 which fit to all of the above stated classifications.

Millennials or Generation Y is also known as the Entitled Generation, Echo Boomers or the Net Generation [18]. Viacom International Media Networks (2012) estimated that with a 2.5 billion Millennials worldwide, approximately one third of the global population they are forming the biggest generation of all [23], [24]. There are between 50 and 80 million employees in the U.S. workplace [25]. According to an article of Forbes in 2012, it is anticipated that Millennials will hold $50 \%$ of the USA workforce by 2020 and $75 \%$ of the global workforce by 2030 . They represent also around $35 \%$ of the Turkish population due to a report published by Hurriyet newspaper (2014).

The Millennials is an important cohort and target audience for retailers and consumer product companies because of its size and significantly high purchasing power. Studies show that the Millennials has different values, characteristics and behavior compared with the other generations [26].

It is obvious that age is also crucial as well as gender, race and culture as an element that defines what connects some group of people together [20]. Consumers' age intervals require significant interest from marketers, 
especially age has a key role related to brand choice and loyalty [27]. For long term and sustainable success in branding an early success with young consumers becomes imperative. It seems that these young adults are Millennials for marketers. In this sense in segmentation, positioning and marketing communication age factor should be taken into account. Therefore it is crucial for the marketers to understand the inner world and the value systems of the Millennials.

Tulgan and Martin describe Generation $\mathrm{Y}$ as a generation of new confidence, upbeat and full of self-esteem, the most educated generation in history, a generation paving the way to a more open, tolerant society [28]. Many authors agree that, Generation $\mathrm{Y}$, is a tech savvy, multi-tasker, team player, autonomous, self-centered, ambitious and an informal generation[18], [20], [29], [30]. Studies show that they are the most socially conscious generation ever [20], [30], [31]. They spend more than all other generations. According to an "Advertising Age" report, by 2017 it is anticipated that they will spend more than $\$ 200$ billion and $\$ 10$ trillion in their lifetimes. Besides they have low levels of brand loyalty [30]. This makes them the most difficult generation to manage ever. Another important fact is that Generation $Y$ is the fastest-growing segment of the workforce. They are good at challenging works and they are creative, they love freedom and flexibility, and hate micromanagement [20]. Another reason of why the adult Gen Yers should be investigated by the marketers is their powerful position in the work life. They are economically independent and they will be at top management for the next decade. According to a research, Millennials are found as the hardest to reach through advertising [31]. GenYers celebrate individuality and diversity, but interestingly are still keen of group work [31].

Gen Yers need to be examined case-by-case basis to understand consumer behavior pattern and identify the segmentation criteria [30]. Researchers should take into account the cross cultural generational differences and need to clarify what causes worldwide differences in generations' attitudes and behaviors. Attitudes, beliefs, and work expectations may differ by country [29]. Since 1981 the World Values Survey (WVS) is being undertaken in several different countries in order to provide insights related to value systems of different cultures and underline the trends [32]. The survey points out that there are two broad dimensions which separate value systems in different cultures first is traditional vs. secular-rational values dimension and the other is "survival vs. self-expression values" [32]. Turkey is holding a critical position in this definition since it's the only secular country in which $99 \%$ of the population is Muslim. Therefore, examining the value system of Generation Y in Turkey becomes very important and precious to provide meaningful information about their behaviors.

\section{Methodology}

In order to provide highlights to marketing professionals it is important to investigate the prominent values of Generation Y. In this study the value system of Turkish Gen Yers who are in the work life is investigated. The
Generation Yers, are defined as the working adults born between 1981and 2000. The research contributes to extant marketing literature in a number of ways. It addresses the values of Generation Y in an emerging country Turkey. The result of this study is expected to lead to the comparison with other countries' Millennial populations. The results are also expected to shed light to marketing decisions for the brands and companies targeting the Gen Y. It is also important to underline that there is limited research about the beliefs and values of adult working group of Gen Yers. The qualitative methods used in this study are expected to provide deep insight on the values of $\mathrm{Y}$ Generation in Turkey.

Qualitative research methodology provides valuable information to the deep understanding of consumer behavior and the reasons behind that behavior [33], [34]. Qualitative methods are useful to explore the inner world of human being and reach valuable and hidden inferences [34].

In the study, four focus groups (each consisting of seven or eight participants) and ten in-depth face-to-face interviews were conducted. The participants were all working adults belonging to Gen $\mathrm{Y}$ from different sectors in total 40Gen Yers have been interviewed.19 of the participants are female, the average work life of the participants is around 7 years. The participants were mostly well educated with a university degree. 8 of them have high school diploma, only one has primary education and the rest have undergraduate(20) or graduate degree (5).

A structured protocol has been followed in focus group and in-depth interviews. Each focus group meetings lasted around two hours. The in-depth interviews were conducted with the same protocol. All the interviews were audio taped with the permission of the respondents. The respondents are encouraged to talk freely and extensively about their values and the underlying motives.

So as to reach valid inference the data is analyzed through content analysis [35]. Two researchers have decoded the interviews. Two independent sorters, who have sociology and communication backgrounds, grouped the themes under independent meta-themes. Later, the sorters and the researchers discussed the analysis and agreed on a final list. In total 50 themes have been classified under 8 metathemes. Finally, two independent judges who have a marketing background placed these themes under these agreed meta-themes. The reliability of the classification was measured by calculating the agreement level between the judges [36]. The agreement level was found to be statistically significant with $86.63 \%$ reliability for the themes (see Appendix A for the reliability figures).

\section{RESULTS AND DISCUSSIONS}

With respect to the results of the focus groups and in depth interviews, 50 meta-themes are determined and categorized under 8 dimensions. Some of the values in this study can be placed more than in one single dimension. Schwartz has also pointed this complexity in his study 2006. The output of judges is analyzed deeply and it is seen that the most complicated part was placing the values for success and power dimensions. Although the results of this study has similarities with the results of the previous research 
there are some new findings regarding the values of Turkish Gen Yers which will be discussed below. The list of 50 value items and 8 meta-themes are summarized in Table II.

\begin{tabular}{|c|c|}
\hline UNIVERSALISM & $\begin{array}{l}\text { Respect to each other, Wisdom, Social Justice, } \\
\text { High morality, Freedom, A world of beauty, } \\
\text { Peace, Protecting the environment, Honesty } \\
\text { Equality }\end{array}$ \\
\hline CONFORMITY & $\begin{array}{l}\text { Trust to each other, Empathy, Obedient, } \\
\text { Respect to traditions, Self devotion, Desire to } \\
\text { be loved, Sincerity, Honoring parents and } \\
\text { elders, Sharing, Loyalty }\end{array}$ \\
\hline HEDONISM & Pleasure, Enjoying life, Self indulgent \\
\hline SECURITY & $\begin{array}{l}\text { Family security, Healthy, Social order, Sense } \\
\text { of belonging }\end{array}$ \\
\hline SUCCESS & $\begin{array}{l}\text { Productivity, Capable, Ambitious } \\
\text { Creative, Hardworking, Responsibility, } \\
\text { Clever, Self confident } \\
\text { Dynamism, Target-orientedness }\end{array}$ \\
\hline POWER & $\begin{array}{l}\text { Authority, Prestige, Freewill, Independent, } \\
\text { Brave, Social Status, Financial Power }\end{array}$ \\
\hline SELF RESPECT & Self esteem, Well groomed \\
\hline SPIRITUALITY & $\begin{array}{l}\text { Faithful, Inner harmony, Positive thinking, } \\
\text { Accepting portion in life }\end{array}$ \\
\hline
\end{tabular}

\section{A. Universalism}

These are the values that will make the world a place more habitable, in other words the very basic personal values that should be valuable for all human beings regardless of their race or nationality. "Respect to each other," "wisdom" and "honesty" are most prominent values within the universalism dimension for the working Turkish adult Gen Yers. The universalism dimension within this study is quite consistent with Schwartz's Value Survey [1] however even though "respect to each other" appeared to be one of the most important values in this study and it does not exist in SVS. Another value which is emphasized through this study is "good morality". Honesty and high morality are also found to be among the most crucial values for Gen Yers in another study realized in Turkey which was investigating college student Gen Yers [37]. Another consistent result with other studies is that they are socially conscious about the environmental issues [30], [31].

\section{B. Conformity}

Includes the values which are essential in building good and successful relations with others in the society. Although the same dimension is supplied by SVS (2012), the items in this study are broader and deeper. "Trust" and "loyalty" are the most prominent values which are not listed in SVS (2012) [1]. Furthermore, this result is not consistent with the findings of Tulgan and Martin 2006 which indicates that Gen Yers are prone to leave their jobs as soon as they find a better position in another organization [20].In another study carried out in Turkey with studying Gen Yers, it has been found that they have conditional loyalty meaning that whenever there is a better opportunity they would immediately take it [37].

Trust is a critical value should be investigated sociologically among Turkish people as stated in WVS 2011 by Esmer. The results of WVS 2011 indicate that Turkish people do not trust each other and therefore they have a strong need of trust [32].

The respondents refer that empathy is crucial in interpersonal relationships. The Turkish working Gen Yers believe in the importance of empathy and expect empathy from others.

Another important finding related to the conformity dimension is that the respondents of the study have mentioned a strong desire to be loved when they were asked to evaluate "thetrichotomy of needs motivation theory," developed by David McClelland (1987) [38]. During the content analysis the respondents were asked to evaluate the McClelland's trichotomy; need for affiliation, need for achievement and need for power. The results indicate that the rate of preference for power need and success needs are found to be very important but in a way related to each other. However, the desire to be loved appeared to be the most prominent need.

\section{Hedonism}

Hedonistic values are in perfect match with those of SVS (2012). The respondents mentioned these items not in the context of work life but rather as general values directing their life. Several research have investigated the Gen Yers values, needs and expectations concerning the work environment not their overall life value structures [20], [25], [28], [29], [39]. Therefore, hedonistic dimension does not exist in that kind of research. This study also proves that Gen Yers connect hedonistic values not with the work life alone but with their whole living philosophy.

Previous studies supported hedonistic dimension with the statement that Gen Yers are looking for happiness and joy in the working place if they won't be able to reach to this value, they will look forward to new opportunities [20]. Another important finding is that they are looking forward at enjoying life in all the aspects of their life. They are keen on spending time with their families instead of working long and stressful hours at work [31]. This study reveals that a balanced private and work life balance is at the center of their expectations.

\section{Security}

The value items that enhance the feeling of being secure in daily life are all listed in security dimension. All four items are available in SVS (2012). Although Turkish population is known with its concern related to national security (WVS, 2011), interestingly, national security has not been mentioned by the respondents in this study.

The most predominant value under security dimension is the family security. This result is inevitable since Gen Y members are known to have received considerable support from their families. It should be also underlined that the study reveals that Turkish adult Gen Yers have very strong ties with their families. Gen Yers parents adored them and feed them with self-confidence as Tulgan indicated in 2009 [40]. Being a good parent is the top of the priority for $52 \%$ of Gen Yers [25]. The respondents indicated that family is the main institution that shapes their values and where they will unconditional love and security.

\section{E. Success}

According to the participants of this study success and 
power dimensions are interlinked and may be used interchangeably. However, the success dimension is expressed to involve the intrinsic values that are related with the individual's self. On the other side, power dimension includes the extrinsic values related with the group's or society's members' perception. Another finding is that the value items listed under the success dimension are antecedents to achieve success. Since the adult Gen Yers are from the work life, the values related with success form quite a long list. Being productive, hardworking, responsible have appeared to be the most important ones by them. Consistent with the previous literature "being creative" and "capable" also are strong values to achieve success. These results are supported with other studies; Gen Yers are more happy when they are productive [29], creative, [20] and capable [29].

The Turkish adult Gen Yers stated that they are selfconfident and optimistic as Dias (2013) supported too [41]. Cole et al. (2002), reasoned this situation with the fact that this group members received enormous care and attention from their families therefore they are more self-confident and optimistic [39].

The "achievement" dimension of Schwartz (2012) is enlarged by this study with new value items such as productivity, hardworking, creativity and responsibility. None of these four values are available in the total list of 57 value dimensions of Schwartz (2012).

\section{F. Power}

Power dimension is considered to be important but less meaningful than the desire to be loved. The Gen Y adults who have participated to the study need power to make their life more comfortable and to satisfy their status needs. This dimension includes social status, prestige, authority and especially independence. In this dimension financial power appeared to be the most crucial value. They believe that having power will provide them independence not only in economic means but also related to choosing the life style they wish without the consent of others. As previous the studies supported they are conscious about their status and image in the society which in return they believe brings power [41]-[43]. The value items appeared in this dimension are quite consistent with those of Schwartz (2012).

The main distinction between power and success dimensions is that; the value items stated below success dimension are the antecedents to achieve success in life. Whereas, the value items defined under power dimension seem to more the consequences of having power.

\section{G. Self-Respect}

Self-respect dimension is directly related with promotion of the "self". The adult Gen Yers in work force believe that they should invest on themselves both physically and mentally. In their social life they are keen on being well groomed since they are a member of a generation that has a high spending power. Having self-esteem and well groomed are two the values that are not listed in Schwartz value items. There are several studies about Gen Yers' attitudes toward fashion and apparel choice behaviors [41]-[43]. However, being well groomed is mentioned as an important value in many studies concerning Gen $\mathrm{Y}$ values. On the other hand, as Parker et al., 2014 point out that they are very concerned about their appearance and they prefer to reflect their own style instead of sticking on the fashion trends [43].

\section{H. Spirituality}

This dimension consists of items related with inner peace and harmony and relation with God. In this study four value items are collected under this heading. Many of the Turkish adult Gen Yers who have participated to this study do not declare themselves as devout but they are faithful, they believe in God. They pray to have inner harmony. They believe that thinking positive will result with positive outcomes. Accepting portion in life without questioning is considered to be an important quality. However, it has also be noted that there is an increasing trend among certain groups of Turkish society in terms of following the formal rules of religion as a part of the daily life style [32].

\section{MANAGERIAL IMPLICATIONS}

The findings of the study provide valuable insights for several disciplines but in this section it has been focused on marketing implications.

The Gen Yers love dynamism and change so it would be difficult for marketers to build brand loyalty. On the other hand, since they value trust once brand loyalty is established the Gen Yers can be brand advocates.

- Another predominant value for the Gen Yers is "respect"; so they will probably ask for respect at all levels during the communication and consumption processes.

- The communication methods and messages should be clever, creative and entertaining for Gen Yers to be remembered among many other alternatives.

- The Gen Yers value their families, show respect to the elders and traditions so the messages in the ads may involve related messages so as to be seen and remembered.

- As mentioned before Gen Yers are the most socially responsible generation of all; so marketers can enhance their strategies by developing and adopting some social responsibility projects.

- It is also known that they are from a health conscious generation; they are willing to pay more to healthy, organic, clean products not only for themselves but also for their families. Having a positive social impact and being loved within the society is significant for Gen Yers as a result they are willing to spend more on prestigious trendy, fashionable brands and products.

- Gen Yers have desire to feel sense of belonging because of safety reasons thus the marketers should provide them a community and reward their loyalty with several different programs.

\section{SUGGESTIONS FOR FURTHER RESEARCH AND LIMITATIONS OF THE STUDY}

Since the study is an exploratory one in nature its results cannot be generalized. Also the study's results are relevant for only one country which is Turkey. On the other hand, it provides valuable information while analyzing the values of a generational cohort namely Gen Yers in an emerging 
country, namely Turkey. It is important to note that values may differ from one country another as well as the Gen Y profiles; so cross cultural research is very valuable for both academics and practitioners. Gen Yers are a complex generation thus their needs and wants should be understood to anticipate their behaviors and attitudes toward a product, a campaign, brand or company. So if the results can be tested cross culturally it would be beneficial at all means. Finally, the meta-themes and the themes underlined in this study should be empirically tested in a future empirical research.

\section{CONCLUSION AND FINAL REMARKS}

The findings that shed light on the values of Turkish Gen Yers can be interpreted and used for several reasons: (1) for all local and global companies which are already operating or are planning to operate in Turkey, which target Gen Y with their products and services (2) for the companies who have the Gen $\mathrm{Y}$ in their workforce in order to attract, motivate and maintain them (3) for all the fields where the individuals and their behavior in the society have to be examined.

However, the findings have to be interpreted carefully. The results of this study highlight that the value structure of adult working Gen Yers is complex. The respondents state the importance of loyalty and respect but they also like dynamism and change. They claim to be independent and self-directed but, they have also put the desire to be loved at the top. Here comes the question: How can they be loved by everyone if they do not live in conformity with the majority? Another contradiction happens when they value being ambitious and hardworking on one side and accepting portion in life on another. These two success related values are in contradiction with the definition of accepting portion in life which means doing ones best to achieve the expected result but then leaving the result to God or fate and accepting the results in peace.

An empirical study will be carried out to find out the significance of the value items underlined in this qualitative study, will be carried out to find another qualitative work may be conducted to understand, furthermore the most prominent values of Turkish working Gen Yers.

\section{APPENDIX A: METHODOLOGY OF CONTENT AND RELIABILITY ANALYSIS}

Content analysis usually yields numerical descriptions of the data. Texts are summarized and classified into fewer content categories. This method requires the objective, systematic and quantitative description of the content of communication [36]. Following the requirements, an analysis of the texts obtained from depth interviews and focus groups is performed and the stages are as follows:

- The researchers code the participants' answers into a list of themes $(n)$,

- The researchers group the themes into exclusive and comprehensive categories,

- Two independent sorters $(N)$ group the themes under certain categories,

- The researchers and the sorters discuss the reasoning behind the classification and come up with an agreed categorization

- Different from the sorters, two people from the field are assigned as judges and grouped the themes under the agreed categories.

38 out of 50 themes matched and the reliability and the zscore was calculated to assess the statistical significance of the match between judges [44].

$n$ : total number of items: 50

$E$ : expected number of matches or $n^{*}(1 /$ number of categories)

$p$ : probability that two judges assign a theme to the same category: $1 / 8$

$k$ : items matched: 38

Number of matches: 38

Percentage of Matches: $76 \%$.

Z score: 13.58

$$
z=\frac{k-E}{\sqrt{n p(1-p)}}
$$

The percent agreement between the judges was found to be statistically significant $(z=13.58$ which exceeds $z$-score of 2.33 corresponding to $\alpha=0.01$ ) with $86,63 \%$ reliability related to the value themes. The reliability figure was calculated by the following formula:

$$
R=\frac{N * \text { Average Agreement }}{[1+(N-1) * \text { Average Agreement }]}
$$

$N$ : Number of Judges: 2

Average Agreement: 38/50

$R=0.8663$

\section{REFERENCES}

[1] S. H. Schwartz. (2012). An overview of the Schwartz theory of basic values. Online Readings in Psychology and Culture. [Online]. 2(1). Available: http://dx.doi.org/10.9707/2307-0919.1116

[2] G. Meredith and C. D. Schewe, Defining markets, defining moments: America's 7 Generational Cohorts, Their Shared Experiences, and Why businesses Should Care, John Wiley \& Sons, New York, 2002.

[3] G. Meredith and C. D. Schewe, "Segmenting global markets by generational cohorts: Determining motivations by age," Journal of Consumer Behavior; Vol. 4, 1, pp. 51-63, 2004.

[4] D. E. Vinson, J. E. Scott and L. M. Lamont, "The role of personal values in marketing and consumer behavior," Journal of Marketing, vol. 41, no. 2, pp. 44-50, 1977.

[5] Istanbul Chamber of Certified Public Accountants. (2014). Turkey's Creative Future; Gen Y Report. [Online]. Available: http://archive.ismmmo.org.tr/

[6] P. Homer and L. Kahle, "A structural equation test of the "Valueattitude-behaviour hierarchy," Journal of Personality and Social Psychology, vol. 54, pp. 638-64, 1988

[7] S. H. Schwartz, "Are there universal aspects in the content and structure of values?" Journal of Social Issues, 50, pp. 19-45, 1994.

[8] B. M. Meglino and E. C. Ravlin, "Individual values in organizations: Concepts, controversies and research," Journal of Management, vol. 24, no. 3, pp. 351-389, 1998.

[9] T. Rintamaki, A. Kanto, H. Kuusela, and M. Spence, "Decomposing the value of department store shopping into utilitarian, hedonic and social dimensions," International Journal of Retail \& Distribution Management, vol. 34, no. 1, pp. 6-24, 2006.

[10] M. Rokeach, The Nature of Human Values, The Free Press., New York, 1973.

[11] M. Rokeach, Beliefs, Attitudes, and Values: A Theory of Organization and Change, CA: Jossey-Bass, San Francisco, 1968.

[12] W. Bearden, R. G. Netemeyer, and K. L. Haws, Handbook of Marketing Scales Multi-item Measures for Marketing and Consumer Behavior Research, Sage Publications, California, 2011. 
[13] S. H. Schwartz, "Basic human values: Theory, measurement, and applications" Revue Française de Sociologie, vol. 47, no. 4, 2006.

[14] D. Spini, "Measurement equivalence of 10 value types from the Schwartz value survey across 21 Countries," Journal of CrossCultural Psychology, vol. 34, no. 1, 2008.

[15] C. P. Egri and D. A. Ralston, "Generation cohorts and personal values: a comparison of China and the United States," Organization Science, vol. 15, no. 2, pp. 210-220, 2004.

[16] J. B. Balda and F. Mora, "Adapting leadership theory and practice for the networked, Millennial generation," Journal of Leadership Studies, vol. 5, no. 3, pp. 13-24, 2011.

[17] N. Howe and W. Strauss, "Millennials rising: The next greatest generation," Vintage Books, NewYork, 2000

[18] T. L. Cekada, "Training a multigenerational workforce," Professional Safety, vol. 57, no. 3, pp. 40-44, 2012.

[19] T. Beekman, "Fill in the generation gap," Strategic Finance, vol. 93, no. 3, pp. 15-17, 2011.

[20] B. Tulgan and C.A. Martin, Managing the Generation Mix, HRD Press Inc., Canada, 2006.

[21] Y. Kavounis, "The millennial affect," Brand Strategy, vol. 226, p. 49, 2008.

[22] L. G. Schiffman and L. L. Kanuk, Consumer Behavior, 7th ed., Prentice-Hall, Inc., Englewood Cliffs, 2010.

[23] D. Gursoy et al., "Generational differences in work values and attitudes among frontline and service contact employees," International Journal of Hospitality Management, vol. 32, pp. 40-48, 2013.

[24] M. Sedrak and T. Cahill, My New Organization Just Doesn't Understand Me: The Millinneal's Dilemma! ACHE, Chicago, IL, 2012.

[25] S. Bannon, K. Ford, and L. Meltzer, "Understanding millennials in the workplace," CPA Journal, vol. 81, no. 11, pp. 61-65, 2011.

[26] A. Parment, "Generation Y vs. baby boomers: Shopping behavior, buyer involvement and implications for retailing," Journal of Retailing and Consumer Services, pp. 189-199, 2013.

[27] A. Kumar and H. Lim, "Age differences in mobile service perceptions: comparison of Generation Y and baby boomers," Journal of Services Marketing, vol. 22, no. 7, pp. 568-577, 2008.

[28] B. Tulgan and C. A. Martin, Managing Generation Y: Global Citizens Born in the Late Seventies and Early Eighties, HRD Press, Inc., Amherst, Massachusetts, 2001, p. 4.

[29] J. Kilber, A. Barclay, and D. Ohmer, "Seven tips for managing Generation Y," Journal of Management Policy and Practice, vol. 15, no. 4, pp. 80-89, 2014

[30] C. Gurau, "A life-stage analysis of consumer loyalty profile: Comparing Generation X and Millennial Consumers," Journal of Consumer Marketing, vol. 29, no. 2, pp. 103-113, 2012.

[31] J. Wolburg and J. Pokrywczynski, "A psychographic analysis of Generation Y, college students," Journal of Advertising Research, pp. 33-53, 2011.

[32] World Values Survey Results Turkey. (2011). [Online]. Available : http://www.worldvaluessurvey.org

[33] W. L. Wilkieand E. S. Moore, "Scholarlyresearch in marketing: Exploringthe '4eras' of thought development," Journal of Public Policyand Marketing, pp. 116-146, 2003.

[34] S. Levy, "Theevolution of qualitativeresearch in consumerbehavior," Journal of BusinessResearch, vol. 58, pp. 341-347, 2005.

[35] R. P. Weber, "Basic contentanalysis," Sage University Papers, Sage Publications, California, 1990.
[36] M. R. Zimmer and L. G. Linda, "Impressions of retail stores: A content analysis of consumer images," Journal of Retailing, vol. 64, no. 3, pp. 280-293, 1988

[37] B. Bicer et al.," "Targeting millennials in an emerging market: A qualitative study on the value systems of Generation Y in Turkey," in Proc. V. European Conference on Social and Behavioral Sciences, Baltic Institute of Humanities, St Petersburg, Russia, September 1114, 2014.

[38] D. McClelland, Human Motivations, Cambridge University Press, NY, 1987.

[39] G. Cole, R. Smith, and L. Lucas, "The debut of Generation Y in the American workforce," Journal of Business Administration Online, vol. 1, no. 2, 2002.

[40] B. Tulgan, Not Everyone Gets a Trophy: How to Manage Generation Y, California: Jossey-Bass, San Francisco, 2009.

[41] P. L. Dias, "Generational buying motivations for fashion," Journal of Fashion Marketing and Management: An International Journal, vol. 7, Iss. 1, pp. 78-86, 2013.

[42] C. Bakewell, V. Mithchell, and M. Rothwell, "UK generation Y male fashion Consciousness," Journal of Fashion Marketing and Management, vol. 10, issue 2, pp. 169-180, 2006.

[43] R. S. Parker, C. S. Simmer, and A. D. Schaefer, "An exploratory study: Gen Y males and their attitudes toward fashion," Academy of Marketing Studies Journal, vol. 18, no. 2, p. 79, 2014.

[44] O. R. Holsti, Content Analysis for the Social Sciences and Humanities, Adisson-Wesley, 1969.

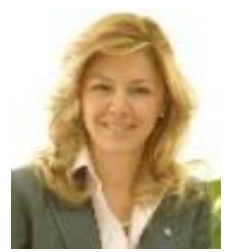

Ipek Altinbasak-Farina was born on December 15, 1966. She received her BA degree in business administration from Bogazici University, Istanbul, Turkey and her MBA from West Georgia University, USA. After graduation, she worked as a brand manager, marketing manager and new product development manager in the FMCG sector at multinational companies. She got her $\mathrm{PhD}$. in marketing from Bogazici University and joined Bahcesehir University in 2004.

She is now working in the Faculty of Economics, Administrative and Social Sciences at Bahcesehir University, Istanbul, Turkey.

Assoc. Prof. Dr. IpekAltinbasak-Farina is served as the director of the graduate School of Bahcesehir University, Istanbul, Turkey. She established more than 20 master programs. She teaches several courses on marketing, brand management, and research at undergraduate, graduate and $\mathrm{PhD}$ levels. Among her research interests are country image/place marketing, brand management, education marketing and service marketing.

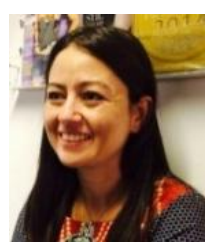

Gozde Guleryuz-Turkel was born on November 20, 1978. She received her BA degree in business administration from Bilkent University, Ankara, Turkey and her MBA from Sabanci University, Istanbul, Turkey. After graduation, she worked as a brand manager and marketing manager in FMCG and media sectors. She is studying her PhD degree in Bahçeşehir University, Istanbul, Turkey and working as the marketing manager of Turkuvaz Magazine Group. 